\title{
SURFACE EXTENDED X-RAY ABSORPTION FINE STRUCTURE OF LOW-Z ADSORBATES USING FLUORESCENCE DETECTION
}

\author{
J. Stöhr* and E.B. Kollin \\ Corporate Research Science Laboratories \\ Exxon Research and Engineering Company \\ Annandale, New Jersey 08801 \\ D.A. Fischer, J.B. Hastings, and F. Zaera \\ National Synchrotroni Light Source Department \\ Brookhaven National Laboratory \\ Upton, New York 11973 \\ F. Sette \\ AT\&T Bell Laboratories \\ Murray Hill, New Jersey 07974
}

Abstract

Comparison of $X$-ray fluorescence yield (FY) and electron yield surface extended $X$-ray absorption fine structure spectra above the $S$ K-edge for $c(2 \times 2) S$ on $\mathrm{Ni}(100)$ reveals an order of magnitude higher sensitivity of the FY technique. Using FY detection thiophene $\left(\mathrm{C}_{4} \mathrm{H}_{4} \mathrm{~S}\right)$ chemisorption on $\mathrm{Ni}(100)$ is studied with $S$ coverages down to 0.08 monolayer. The molecule dissociates at temperatures as low as $100 \mathrm{~K}$ by interaction with fourfold hollow $\mathrm{Ni}$ sites. Blocking of these sites by oxygen leaves the molecule intact.

* New Address: IBM San Jose Research Laboratory, 5600 Cottle Road, San Jose, CA 95193

\author{
Research Supported by the \\ OFFICE OF BASIC ENERGY SCIENCES \\ U.S. DEPARTMENT OF ENERGY \\ WASHINGTON, D.C. \\ NATIONAL SYNCHROTRON LIGHT SOURCE DEPARTMENT \\ $\checkmark$ BROOKHAVEN NATIONAL LABORATORY \\ ASSOCIATED UNIVERSITIES, INC. \\ Under Contract No. DE-AC02-76CH00016 with the \\ U.S. Department of Energy
}


This report was prepared as an account of work sponsored by an agency of the United States Government. Neither the United States Government nor any agency thereof, nor any of thei- employees, nor ary of their contractors, subcontractors, or their employees, makes any warranty, expressed or implied, or assumes any legal liability or responsibility for the accuracy, completeness, or usefulness of any information, apparatus, product, or process disclosed, or represents that its use would not infringe privately owned rights. Reference herein to any specific commercial product, process, or service by trade name, trademark, manufacturer, or otharwise, does not necessarily constitute or imply its endorsement, recommendation, or favoring by the United States Government or any agency thereof. The views and opinions of authors expressed herein do not necessarily state or reflect those of the United States Government or any agency or subcontract thereof. 
Surface extended $x$-ray absorption fine structure (SEXAFS) and near edge $x$-ray absorption fine structure (NEXAFS) studies of chemisorbed species on surfaces are usually carried out by means of electron yield (EY) detection '. Owing to the convenient ultra-high-vacuum (UHV) compatibility of electron detectors and the inherent surface sensitivity of electron detection techniques little effort has been made to use other schemes for measuring the surface absorption coefficient ${ }^{2}$.

In principle, it is well known that the detection of the $x$-ray fluorescence signal associated with the inner shell excitation of atoms diluted in solids or liquids is a powerful method to obtain their local structure by means of EXAFS ${ }^{3}$. Recently, fluorescence yield (FY) EXAFS has also been demonstrated to be a useful probe for certain surface problems, i.e. the structure of high-Z adsorbates (e.g. Au) on low-Z substrates (e.g. Si) ${ }^{4}$. However, since the FY strongly decreases with decreasing atomic number $Z^{5}$, $F Y$ detection has been thought to be $i l l$ suited for obtaining the SEXAFS of low-Z adsorbates on high-Z substrates. This case is of extreme importance because the interaction of low-Z molecules with metal surfaces is the heart of heterogeneous catalysis. It is clear that FY EXAFS studies on such systems, if possible, could revolutionalize traditional surface science in that they wouid allow the study of samples under UHV as well as "real" non-vacuum conditions.

Here we report SEXAFS and NEXAFS studies by means of FY detection above the $K$ absorption edge $(2,470 \mathrm{eV})$ of sulfur ${ }^{6}$, chemisorbed at submonolayer coverage as atoms or in thiophene $\left(\mathrm{C}_{4} \mathrm{H}_{4} \mathrm{~S}\right)$ molecules on $\mathrm{Ni}(100)$. We find that Fy detection is not only feasible but, surprisingly, offers an order of magnitude nigher sensitivity than any $E Y$ detection mode, including A'iger 
electron yield (AY) detection which had previously proven to be particularly suitable for the $S$ on $N i$ system $^{8}$. We also find a significantly reduced background in our soft $x$-ray FY studies as compared to previous FY studies at higher $x$-ray energies ${ }^{3},{ }^{4}$. It is therefore unnecessary to utilize grazing $x$-ray incidence schemes ${ }^{4}$. NEXAFS and SEXAFS spectra obtained by FY detection are used to study the dissociation of thiophene on $\mathrm{Ni}(100)$. We find that the four-fold hollow (FFH) $\mathrm{Ni}(100)$ site is responsible for breaking the S-C bond in the thiophene ring at temperatures as low as 100K. Blocking of these sites by 0 atoms leaves the heterocyclic ring intact upon chemisorption.

Experiments were performed at the Stanford Synchrotron Radiation Laboratory using the "Jumbo" monochromator". With Ge(111) monochromator crystals and storage ring currents of $50 \mathrm{~mA}$, we obtained a flux of about $22^{\star} 10^{10}$ photons/sec at the $S$ k-edge in a $2 \times 4 \mathrm{~mm}$ spot (spectral resolution about 1.5eV). The $S K(2.3 \mathrm{keV})$ radiation from the sample was recorded with a proportional counter ${ }^{10}$ which was mounted in the horizontal plane, perpendicular to the $x$-ray beam, and collected a solid angle of $10 \%$ of $4 \pi \mathrm{sr}$. A $12.7 \mathrm{\mu m}$ thick Be window (40\% transmission) of $5 \mathrm{~cm}$ diameter was used to separate the UHV sample chamber from the P10 (90\% argon, 10\% methane) detector gas. The energy resolution of our counter was approximately lKeV and a discriminator window was centered on the $S K$ peak. The NEXAFS and SEXAFS spectra were recorded for $20^{\circ}$ grazing ( $\vec{E}$ vector close to the sample normal) and $90^{\circ}$ normal $(\vec{E}$ in the surface plane) $\mathrm{x}$-ray incidence angles. The $\mathrm{Ni}(100)$ single crystal was cleaned by $\mathrm{Ar}^{+}$bombardment and oxygen heat treatments to produce a surface free of $C, 0$, and $S$ within the sensitivity limits of Auger electron spectroscopy. To obtain a sharp $c(2 \times 2)$ LEED pattern from atomic $S$ on $\mathrm{Ni}(100)$ the clean annealed surface was dosed with 5 Langmuirs (1 Langmuir (L) 
corresponds to $10^{-6}$ torr ${ }^{*} \mathrm{sec}$ exposure) $\mathrm{H}_{2} \mathrm{~S}$ at $100 \mathrm{~K}$ and then shortly heated to 420K. Thiophene was adsorbed on the clean or oxygen predosed (20L at 30uK, $c(2 \times 2)$ LEED pattern) $\mathrm{Ni}(100)$ surface at 100K. All spectra was recorded at 100K.

The $c(2 \times 2)$ S on $\mathrm{Ni}(100)$ surface, corresponding to half monolayer (ML) coverage, was used to compare $A Y^{8}$ and $F Y$ detection. Fig. I shows SEXAFS spectra recorded with both techniques at grazing $x$-ray incidence and using the same data acquisition time (10 sweeps, 2 sec/point). Spectra obtained at normal incidence gave similar results with a reduction in count rate by a factor of 2.5 for both Jetection modes.

Clearly, the AY and FY spectra in Fig. 1 have comparable signal-to-noise (STN) ratios and analysis of the spectra using the Fourier transform method proved their equivalence. However, the STN ratio is the figure of merit only if the noise of the data is purely statistical. With decreasing concentration of the surface species of interest a sensitivity limit will be set by instrumental noise or structures (INS), e.g. arising from normalization problems, which are independent of counting time. In this case, the criterion of merit is no longer the STN but rather the signal-to-background (STB), defined as the ratio of the edge jump over the signal before the edge. Measurability demands that the STB exceeds the INS. Fig. 1 shows that the FY technique offers an eight times larger STB or sensitivity for S. A similar enhancement is observed at $90^{\circ} x$-ray incidence. This surprising result is due to a much reduced background from the substrate relative to all EY techniques. The background is also significantly smaller than in typical FY measurements at higher $x$-ray energies ${ }^{3}, 4$. Reasons for the enhanced STB are:

1. In contrast to the Auger peak which sits on a significant inelastic electron background', the fluorescence line has almost no background 
originating from inelastic scattering events. The cross-section for inelastic scattering of $x$-rays is small compared to electrons and decreases with decreasing photon energy, thus being more favorable in the soft than hard $x$-ray range.

2. The $x$-ray absorption cross section increases with decreasing photon energy. This enhances the excitation probability of the low $Z$ atom on the surface and decreases the sampling depth in the metal substrate, leading d reduced elastically scattered background.

3. At soft $x$-ray energies, the condition for Bragg scattering is not fulfilled for most crystalline materials such that the Bragg scattered intensity from the substrate is negligible.

4. Even for disorderd substrates, the elastically scattered intensity is reduced at low photon energies because the short wave vector of the incident radiation reduces the accessible volume in reciprocal space.

5. Energy discrimination and windowing of the characteristic fluoresence line does not suffer from similar interference problems as AY detection which for low-Z atoms is often rendered useless by a superposition of Auger and photoemission peaks ${ }^{2}, 11$.

We have used the high sensitivity of the FY technique to study the interaction of thiophene with $\mathrm{Ni}(100)$. Because such studies involved $\mathrm{S}$ coverages of less than $0.1 \mathrm{ML}$ (1 layer of thiophene corresponds to $0.1 \mathrm{ML}$ of S) they are presently not feasible with EY detection. Fig. 2 shows NEXAFS

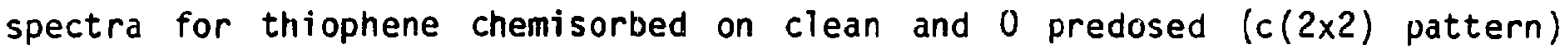
Ni(100) recorded at normal $x$-ray incidence. The spectra have been scaled as indicated to reveal the $S$ coverage which is proportional to the edge jump. As a reference for the edge jump we used the $c(2 \times 2) \mathrm{S}$ on $\mathrm{Ni}(100)$ surface which corresponds to U.5 ML coverage. For thiophene chemisorption on clean Ni(100) 
an exposure of $1 \mathrm{~L}$ produces a coverage of $0.08 \mathrm{ML}$. The NEXAFS spectrum (Fig. 2a) is dominated by a threshold peak $A$ and a broader siructure $C$. For thiophene exposures in excess of $2 L$ another peak $B$ appears which is accompanied by a broader structure $D$. These structures dominate in the $12 \mathrm{~L}$ spectrum shown in Fig. $2 \mathrm{~b}$ which corresponds to a thin muitilayer. Heating the sample diminishes structures $B$ and $U$ until they vanish around 180K. At higher temperatures $(T<600 K)$ the spectra, including that for a $p(2 \times 2)$ LEED pattern which develops around 540K, look like that shown in Fig. 2c which was recorded after heating to $270 \mathrm{~K}$. When scaled to the same size the $1 \mathrm{~L}$ (Fig. 2a) and $270 \mathrm{~K}$ (Fig. 2C) spectra are very similar to each other and to that for $c(2 \times 2) S$ on $\mathrm{Ni}(100)$. Un the other hand, except for peak $A$, the $12 \mathrm{~L}$ multilayer spectrum is almost identical to that for gas phase thiophene ${ }^{12}$. The same comparison holds for the corresponding spectra recorded at grazing incidence (not shown). When the $\mathrm{Ni}(100)$ surface is precovered with a $\mathrm{c}(2 \times 2) 0$ layer the NEXAFS spectra for $\mathrm{IL}$ and $12 \mathrm{~L}$ thiophene exposure at $100 \mathrm{~K}$ are almost identical and consist of peaks $B$ and D only (Figs. $2 d$ and $2 e$ ). These peaks which are characteristic of the thiophene molecule ${ }^{12}$ disappear after heating to higher temperatures (Fig. 2f).

The NEXAFS results shown in Fig. 2 suggest that on clean $\mathrm{Ni}(100)$ thiophene dissociates at temperatures as low as lUUK. The dissociation of the S-C bond is suggested by the absence of resonance, $B$ in Fig. 2a. This resonance is known to be characteristic of the $S-C$ bond from the multilayer thiophene spectra (Figs. $2 b$ and $2 e$ ), gas phase spectra of various molecules with S-C bonds ${ }^{12}$ and from $X_{a}$ multiple scattering calculations ${ }^{13}$. Peaks $A$ and C are associated with $\mathrm{S}-\mathrm{Ni}$ bonds since they are also observed for the $p(2 \times 2)$ and $c(2 \times 2)$ atomic $S$ overlayers on $\mathrm{Ni}\left(100 ;{ }^{8}, 10\right.$. For the oxygen predosed surface only resonances $B$ and $D$ are observed. This and the fact that no $S$ 
remains on the surface upon heating (Fig. 2f) unambiguously proves that thiophene does not dissociate on the $c(2 \times 2) 0$ covered $N i(100)$ surface.

SEXAFS measurements on the same $1 \mathrm{~L}$ samples whose NEXAFS spectra are shown in Figs. $2 a$ and $2 d$ provide further information. Fig. 3 shows their respective Fourier transforms and those of $\mathrm{c}(2 \times 2) \mathrm{S}$ on $\mathrm{Ni}(100)$ and multilayer thiophene. The transform for $1 \mathrm{~L}$ thiophene adsorbed at $100 \mathrm{~K}$ is dominated by the same peak as that for $c(2 \times 2) \mathrm{S}$ on $\mathrm{Ni}(100)$, corresponding to the $\mathrm{S}-\mathrm{Ni}$ nearest neighbor (NN) distance. Analysis of the polarization dependence of the $1 \mathrm{~L}$ spectrum reveals that $S$ sits in the FFH site with a distance of $2.22+0.02 A$, indistinguishable within experimental error ${ }^{14}$ from $p(2 \times 2)^{15}$ and $c(2 \times 2)^{8,16} \mathrm{~S}$ on $\mathrm{Ni}(100)$. In contrast, for the oxygen predosed surface a $1 \mathrm{~L}$ thiophene exposure shows a peak in the Fourier transform at nearly the same position as the thiophene multilayer and (not shown) thiophene gas ${ }^{12}$. Using the known $S-C$ bond length $R=1.714 \AA$ in the thiophene molecule as a reference we obtain a distance of $1.71+0.02 \AA$ for multilayer thiophene and $1.74 \pm 0.04 \AA$ for $1 \mathrm{~L}$ thiophene on 0 predosed $\mathrm{Ni}(100)$. This cleariy demonstrates that for this latter case the molecule remains undissociated upon chemisorption. Furthermore, the absence of a $S-C$ bond related peak around $1.3 \AA$ in Fig. $3 b$ is direct support for our model of dissociated thiophene on the clean Ni(100) surface.

Uur FY NEXAFS and SEXAFS studies suggest the existence of a sitedependent desulfurization process. On the clean Ni(100) surface, S is broken out of the thiophene ring by bonding to FFH Ni sites. Tris occurs already at a remarkably low temperature of lo0k. The dissociated thiophene layer passivates the surface such that with increasing coverage, the molecules remain undissociated in the second and higher layers. For the $c(2 \times 2) 0$ precovered surface, 0 atoms are known to occupy the active FFH Ni sites ${ }^{16}$. Thus blocking of these sites prevents thiophene dissociation. 


\section{Acknowledgements}

We would like to thank T. Oversluizen for help with the detector window design, J. Cerino for his cooperation during the run at SSRL, and J.A. Horsley for providing the results of his unpublished calculations. The work reported here was done at SSRL which is supported by the Office of Basic Energy Sciences of DOE and the Division of Materials Research of NSF. Work performed at BNL is supported by the Division of Materials Sciences, U.S. Department of Energy, under contract DE-AC02-76C400016. 


\section{References}

1. P.H. Citrin, P. Eisenberger, and R.C. Hewitt, Phys. Rev. Lett. 41,309 (1978); J. Stçhr, D. Denley, and P. Perfetti, Phys. Rev. Lett. B18, 4132 (1978).

2. For a review see: J. Stöhr in Chemistry and Physics of Solid Surfaces $V$, Eds. R. Vanselow and R. Howe, Springer Series in Chemical Physics 35 (Springer, Berlin-New York 1984) p. 231; J. Stöhr in X-Ray Absorption: Principles, Applications, Techniques of EXAFS, SEXAFS, and XANES, Eds. R. Prins and D. Koningsberger (Wiley, New York, 1985).

3. J. Jaklevic, J.A. Kirby, M.P. Klein, A.S. Robertson, G.S Brown, and P. Eisenbero:r, Solid State Commun. 23, 679 (1977); J.B. Hastings in EXAFS Spectroscopy, Techniques, and Applications, Eds. B.K. Teo and D.C. Joy, (Plenum Press, New York-London, 1981) p. 171.

4. S.M. Heald, E. Keller, and E.A. Stern, Phys. Lett. 103A, 155 (1984).

5. M.0. Krause, J. Phys. Chem. Ref. Data, 8, 307 (1979).

6. Fluorescence yield $S K$-edge studies for $S$ in coal have been reported by: F.W. Lytle, R.B. Greegor, D. Sandstrom, E.C. Marques, J. Wong, C.L. Spiro, G.P. Huffman, and F.E. Huggins, Nucl. Instr. Methods, 226, 542 (1984); C.L. Spiro, J. Wong, F.W. Lytle, R.B. Greegor, D.H. Maylotte, and S. Lamson, Science, 226, 48 (1984).

7. For a discussion of electron yield detection techniques see: J. Stöhr, C. Noguera, and T. Kendelewicz, Phys. Rev. B30, 5571 (1984).

8. S. Brennan, J. Stöhr, and R. Jaeger, Phys. Rev. B24, 4871 (1981); S. Brennan, Ph.D. dissertation, Stanford University, 1982 (unpublished)。 9. Z. Hussain, E. Umbach, D.A. Snirley, J. Stöhr, and J. Feldhaus, Nucl. Instr. Methods 195,115 (1982). 
10. D.A. Fischer, J.B. Hastings, F. Zaera, J. Stöhr, and F. Sette (to be published).

11. J. Stöhr, Jpn. J. App1. Phys. 17, Suppl. 17-2, 217 (1978); J. Stöhr, L. Johansson, I. Lindau, and P. Pianettas Phys. Rev. B20, 664 (1979).

12. J.B. Hastings, F。Zaera, G.M. Watson, and J. Stöhr (unpublished).

13. J.A. Horsley, private communication.

14. The absolute SEXAFS amplitude for $1 \mathrm{~L}$ thiophene exposure at $100 \mathrm{~K}$ is reduced relative to that for $\mathrm{c}(2 \times 2) \mathrm{S}$ on $\mathrm{Ni}(100)$ by $13+3 \%$ which we attribute to a slightly higher disorder.

15. M. Van Hove and S. Y. Tong, J. Vac. Sci. Technol. 12, 230 (1975)

16. J.E. Demuth, D.W. Jepsen, and P.M. Marcus, Phys. Rev. Lett. 31, 540 (1973). 


\section{Figure Captions}

Fig. 1. Auger electron yield and $x$-ray fluoresence yield SEXAFS spectra above the $S K$ edge for $c(2 \times 2) S$ on $N i(100)$, corresponding to half a $S$ monolayer. Both spectra were recorded at grazing x-ray incidence. Underneath each spectrum the SEXAFS oscillations after background subtraction are shown enlarged.

Fig. 2. Fluorescence yield NEXAFS spectra for thiophene on clean and oxygen predosed $(c(2.2)$ overlayer $) \mathrm{Ni}(100)$ at various exposures and temperatures.
a) $1 \mathrm{~L}$ exposure at $100 \mathrm{~K}$ on $\mathrm{Ni}(100)$.
b) $12 \mathrm{~L}$ exposure at $100 \mathrm{~K}$ on $\mathrm{Ni}(100)$.
c) Sample in b) heated to $270 \mathrm{~K}$.
d) $1 \mathrm{~L}$ exposure at $100 \mathrm{~K}$ on $\mathrm{c}(2 \times 2) 0$ on $\mathrm{Ni}(100)$.
e) $12 \mathrm{~L}$ exposure at $100 \mathrm{~K}$ on $\mathrm{C}(2 \times 2) \mathrm{O}$ on $\mathrm{Ni}(100)$.
f) Sample in e) heated to $270 \mathrm{~K}$.

Fig。 3 Absolute Fourier transforms of fluoresence yield (S)EXAFS spectra for four selected cases.
a) $\mathrm{c}(2 \times 2) \mathrm{S}$ on $\mathrm{Ni}(100) ; 0.5 \mathrm{ML}$ of atomic S.
b) IL thiophene on $\mathrm{Ni}(100)$ at $100 \mathrm{~K} ; 0.08 \mathrm{ML}$ of $\mathrm{S}$.
c) A thiophene multilayer (7 layers) condensed on $c(2 \times 2) 0 / \mathrm{Ni}(100)$.
d) IL thiophene on $\mathrm{c}(2 \times 2) 0$ on $\mathrm{Ni}(100)$ at $100 \mathrm{~K} ; 0.08 \mathrm{ML}$ of $\mathrm{S}$. 


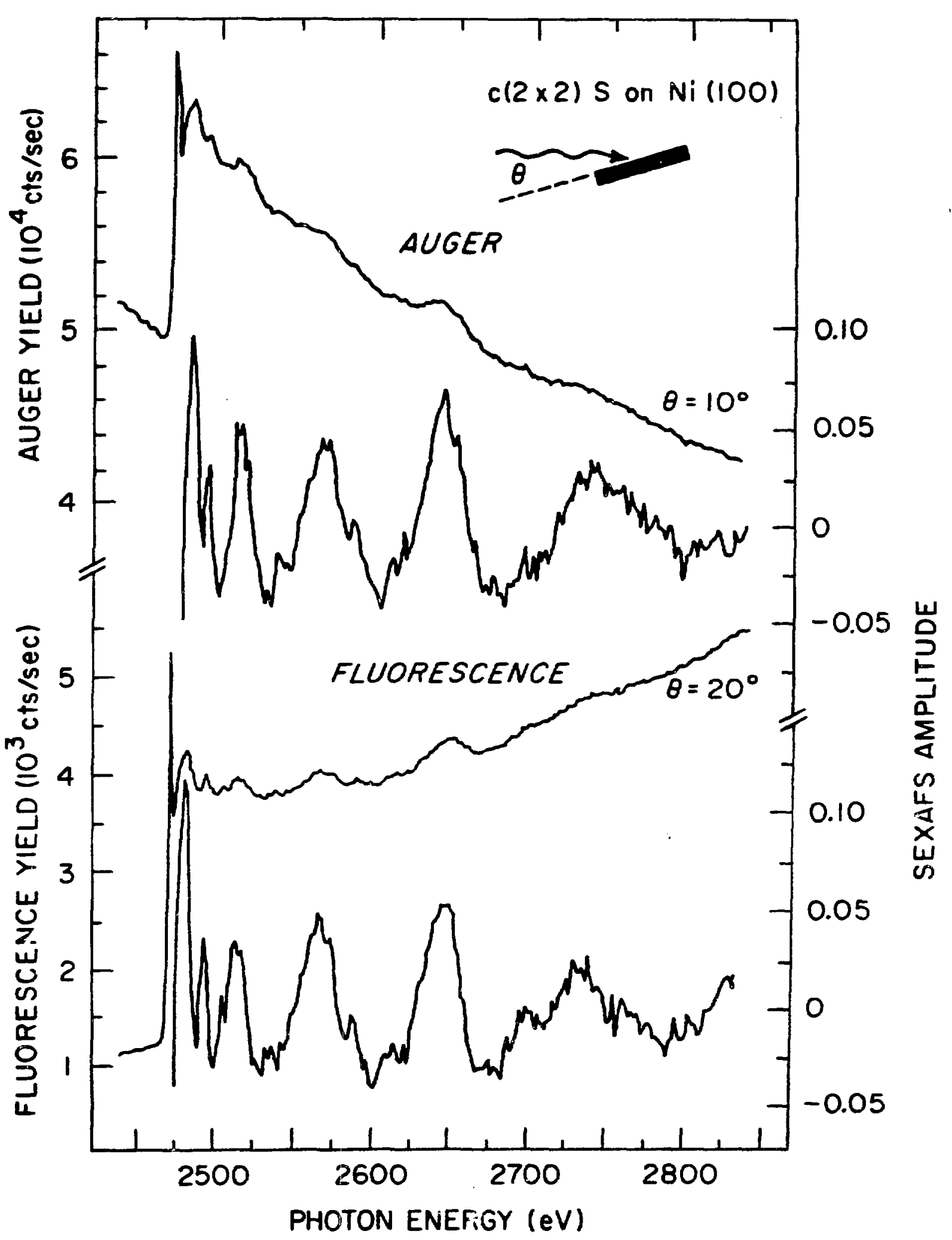

Fig. 1 


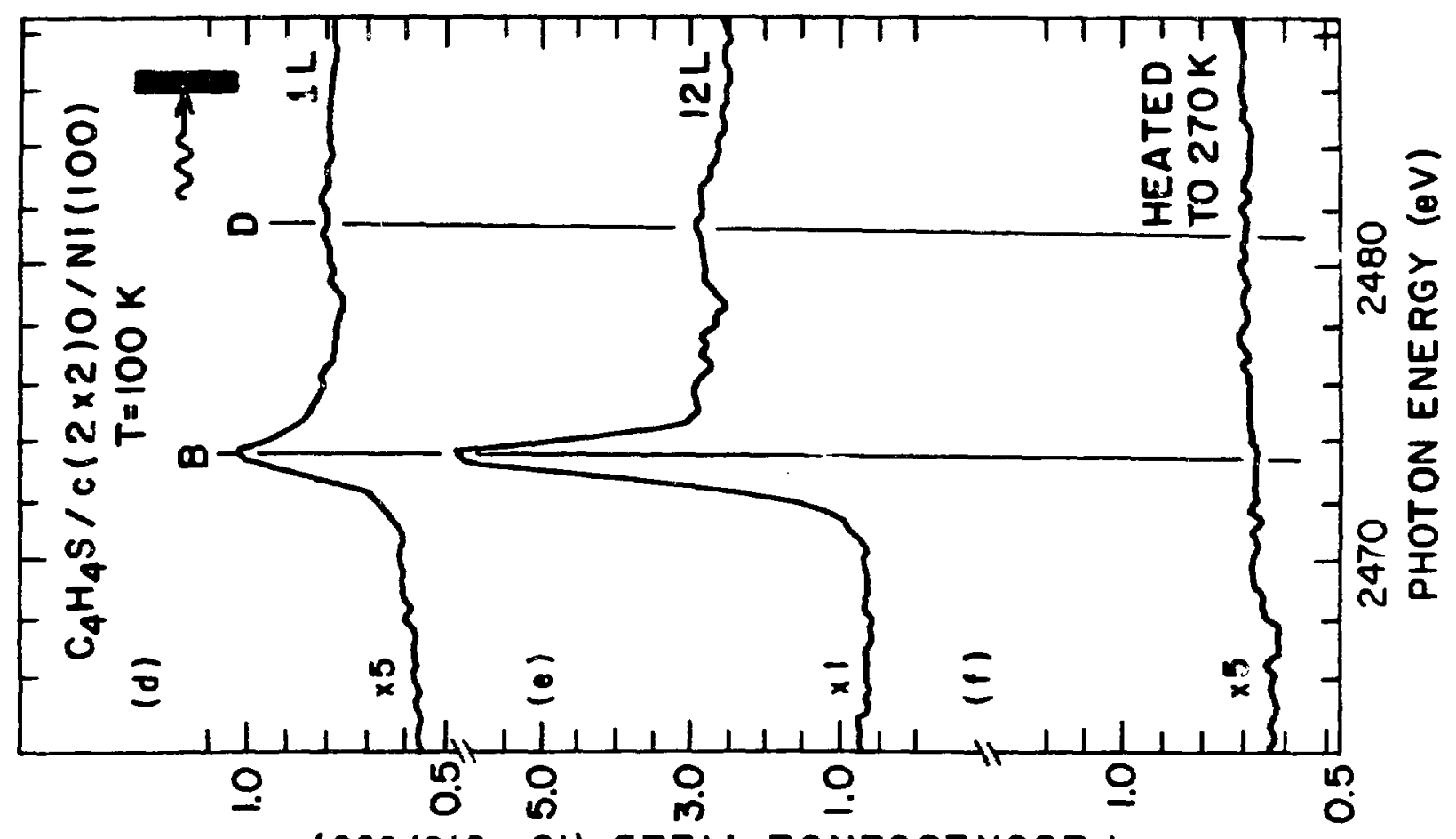

(005/s+o ع

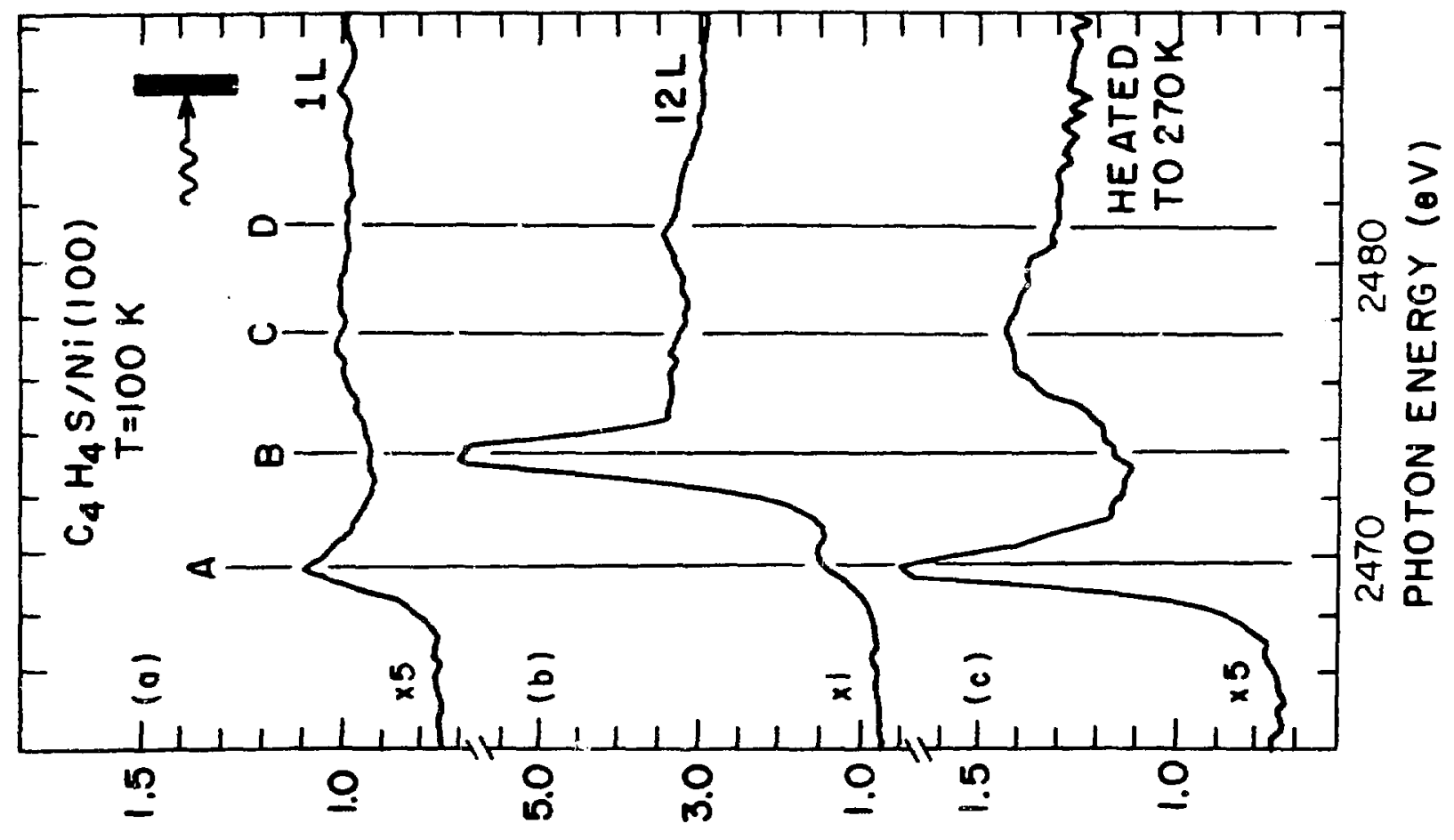

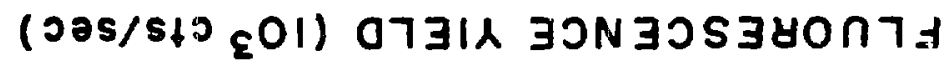

Fig. 2 


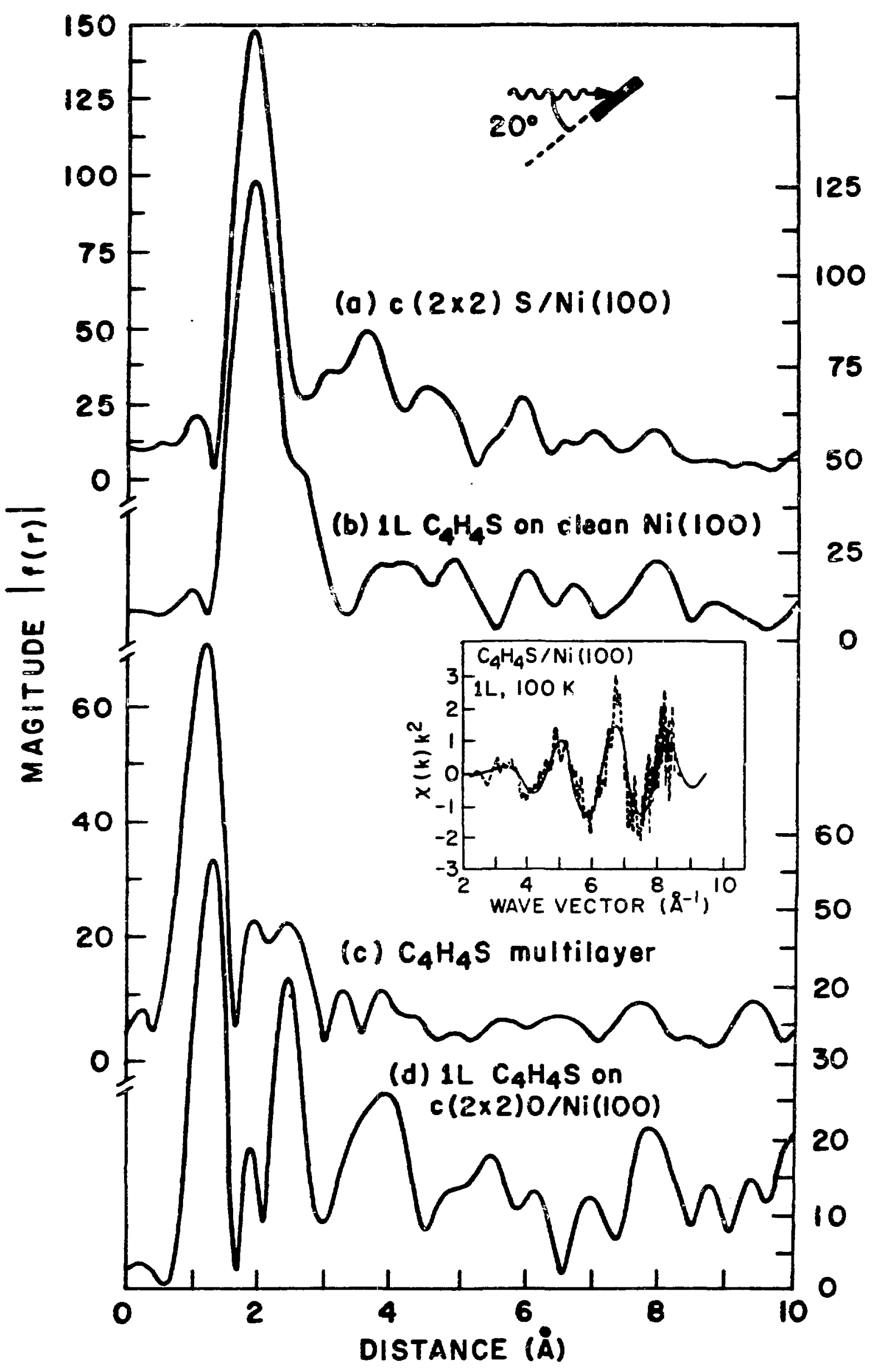

Revised

Fig. 3 